\title{
John Dewey e os embates sobre a psicologia do número
}

\section{John Dewey and the disputes over the psychology of number}

Rafaela Silva Rabelo ${ }^{1}$

\begin{abstract}
Resumo: O presente artigo teve como foco as representações de John Dewey acerca da educação matemática. Especificamente, teve como objetivo explorar as representações de Dewey sobre o ensino de aritmética e o conceito de número, com base em textos que escreveu após a publicação do manual The psychology of number (TPN), do qual foi coautor. Subsidiaram a análise duas cartas de Dewey em resposta a críticas feitas ao TPN e uma resenha. Alguns dos conceitos mobilizados foram representação, campo e lugar social/institucional, com base em Roger Chartier, Michel de Certeau e Pierre Bourdieu. Ficaram evidentes as disputas entre campos, principalmente entre psicologia e matemática, na determinação de quem possui legitimidade para arbitrar sobre o ensino de aritmética. Também transparecem representações de Dewey acerca da educação matemática, sendo que ele reiterou algumas posições presentes no TPN, como a natureza psíquica do número e a relação com os conceitos de medida e razão.
\end{abstract}

Palavras-chave: Educação matemática. Conceitos. John Dewey. Psicologia do número. Ensino de aritmética.

\begin{abstract}
This paper focused on John Dewey's representations about mathematics education. Specifically, the objective was to explore Dewey's representations about the teaching of arithmetic and the number concept, based on texts he wrote after publishing the handbook The psychology of number (TPN) as a coauthor. Some of the sources were two letters written by Dewey, answering critics made of the TPN, and a review. The analysis was based on such concepts as representation, field, and social/institutional place, according to theorists as Roger Chartier, Michel de Certeau and Pierre Bourdieu. It is evident that the disputes between the fields, mainly of psychology and mathematics, concern the determination of who owns legitimacy to deliberate about the teaching of arithmetic. It is also possible to notice Dewey's representations about mathematics education, as he reiterates some aspects present in the TPN such as the psychical nature of number and the relation with the ideas of measurement and ratio.
\end{abstract}

Keywords: Mathematics education. Concepts. John Dewey. Psychology of number. Arithmetics teaching.

\footnotetext{
${ }^{1}$ Universidade de São Paulo (USP), São Paulo, SP, Brasil. Orcid: <http://orcid.org/0000-0002-7883-7914>.

E-mail: <rafaelarabelo@usp.br>.
} 
Considerado um dos principais filósofos da educação dos Estados Unidos e um dos representantes da educação progressiva, John Dewey (1859-1952) foi uma figura importante no cenário educacional no fim do século XIX e principalmente nas primeiras décadas do XX, não apenas nos Estados Unidos, mas em diversos países de diferentes continentes, incluindo o Brasil. Ainda hoje suas obras são amplamente estudadas e seus textos relacionados à educação são considerados atuais, sendo uma referência no campo educacional. A quantidade de pesquisas contemporâneas que tratam de conceitos como experiência, democracia, ética, entre outros, a partir do viés deweyano, comprovam a atualidade da obra do filósofo estadunidense e evidenciam o quanto ainda há para se estudar a seu respeito ${ }^{2}$.

Se, por um lado, os estudos que discutem Dewey a partir dos mais diferentes vieses são fatos incontestáveis, por outro, muito pouca atenção tem sido dada às suas contribuições no campo da educação matemática, visto que as discussões não ultrapassam as rápidas menções ou excertos de citações. Isso se verifica não apenas no Brasil, mas também no país de origem de Dewey, os Estados Unidos. Verifica-se a existência de poucos estudos que buscam discutir a relação entre Dewey e a educação matemática e, especificamente, a quase ausência de pesquisas que se debruçam sobre uma discussão histórica que aponte para as contribuições e/ou apropriações de sua obra na educação matemática ${ }^{3}$. Esta constatação foi possível em consequência dos levantamentos empreendidos em pesquisa de doutorado, na qual um dos objetos foi a circulação e as apropriações de Dewey na educação matemática brasileira ${ }^{4}$.

A ampla recepção de Dewey no campo educacional seria razão suficiente para explorar de que forma se dá sua inserção nas discussões relativas especificamente ao ensino de matemática. Coautor de um manual sobre o ensino de aritmética, publicado em 1895 nos Estados Unidos, a obra tem recebido pouca atenção entre os educadores matemáticos, e mesmo entre estudiosos de Dewey, o que evidencia a necessidade de estudos que explorem suas contribuições para a educação matemática.

$\mathrm{O}$ referido manual, The psychology of number and its applications to methods of teaching arithmetic (MCLELLAN; DEWEY, 1895) teve o educador canadense James Alexander McLellan como primeiro autor. Os estudos que fazem referência a tal obra geralmente incorrem no erro de atribuir a autoria somente a Dewey, ou quando mencionam McLellan, seguem fazendo a análise considerando apenas Dewey. O problema consiste no fato de que em um trabalho que

\footnotetext{
${ }^{2}$ Apenas a título de ilustração, destaco os livros organizados por Popkewitz (2008) e Schiriewer e Bruno-Jofré (2012), os quais têm Dewey como objeto de estudo. Um exemplo mais recente é o dossiê John Dewey's reception and influence in Europe and America, publicado pela revista espanhola Espacio, Tiempo y Educación (2016).

${ }^{3}$ Um estudo exploratório sobre o TPN, que apresenta um levantamento parcial de trabalhos que analisam os escritos de Dewey sobre a educação matemática, foi apresentado por Rabelo (2014). Ainda vale destacar a produção de Kurt Stemhagen, especialmente sua tese de doutorado (STEMHAGEN, 2004), que trouxe discussões sobre a presença da educação matemática em algumas das publicações de Dewey.

${ }^{4}$ Entre 2012 e 2014 foram feitos levantamentos extensivos de pesquisas que relacionassem Dewey e a educação matemática, inclusive durante o estágio de pesquisa, realizado no Teachers College da Columbia University, o qual identificou um número reduzido de referências que trabalhavam a partir de um viés histórico, e, ainda assim, apenas tangenciavam o tema, sem, no entanto, aprofundar a discussão. Conferir os resultados da pesquisa de doutorado em Rabelo (2016).
} 
conta com dois autores, determinar as contribuições de cada um na elaboração do texto é algo que exige, no mínimo, um olhar mais atento.

No caso do manual The psychology of number (TPN), várias abordagens poderiam ser empreendidas no sentido de explorar a contribuição de Dewey, contudo, dentre as possíveis aproximações, assumo que dois aspectos devem ser considerados, de forma a possibilitar uma maior clareza no papel que Dewey desempenhou na sua elaboração. O primeiro diz respeito aos estudos das obras anteriores de Dewey e de McLellan, tendo em vista identificar as ideias de cada um e se as mesmas são incorporadas no TPN. Refiro-me especificamente ao livro Psychology de Dewey, publicado em 1887, e Applied psychology: an introduction to the principles and practice of education, de McLellan, publicado em 1889. O segundo aspecto se refere a textos escritos por Dewey que remetem ao conceito de número, de modo que me refiro às cartas que Dewey escreveu em resposta a críticas feitas ao TPN, publicadas por revistas especializadas, e a uma resenha de sua autoria.

Devido à extensão da discussão, no presente artigo tratarei do segundo aspecto. Nesse sentido, propõe-se explorar as representações de Dewey no que diz respeito ao ensino de aritmética e ao conceito de número, com base nos referidos textos. A relevância da análise dos supracitados textos escritos por Dewey para compreender a sua contribuição na elaboração do TPN leva em consideração, primeiramente, que eles remetem diretamente à sua voz. Ou seja, ao serem escritos por Dewey na tentativa de rebater críticas ao TPN, eles deixam evidente a sua posição e revelam vestígios de suas concepções acerca do ensino de aritmética e do conceito de número. Explorar as representações de Dewey acerca do tema auxilia não apenas a melhor compreender a sua contribuição no TPN, como também, em uma perspectiva mais ampla, fornece evidências de sua posição em relação ao ensino de matemática no final do século XIX, e serve de subsídio para um estudo mais extensivo de sua obra no que concerne à educação matemática. Portanto, o presente artigo contribui tanto nos estudos sobre Dewey quanto nos estudos em história da educação matemática.

Em um primeiro momento, descreverei, em linhas gerais, o manual TPN, de forma a fornecer dados que auxiliem a compreender a relevância das cartas e da resenha que foram escritas por Dewey. Na sequência, analisarei uma resenha escrita por Dewey sobre o livro de Levi Conant, pois tem em comum o fato de Dewey se posicionar sobre conceitos matemáticos, como o conceito de número, e fazer referência à psicologia do número. Em um terceiro momento, abordarei as críticas feitas ao TPN na resenha de Fine e no artigo de Phillips e as respectivas respostas de Dewey, a partir das quais destacarei as ideias-chave que evidenciam as concepções acerca do ensino de matemática e do conceito de número. Por último, articularei as principais concepções de Dewey e os embates que transparecem nos textos analisados.

Apesar dos textos de Conant (1896), Fine (1896) e Phillips (1897) serem muito ricos e trazerem elementos relevantes para discutir concepções acerca do ensino de matemática e do conceito de número no final do século XIX, trarei apenas elementos suficientes para subsidiar a análise dos escritos de Dewey, visto que este último é o objeto de discussão do presente artigo.

Enquanto aproximação teórico-metodológica, explorarei as representações acerca do ensino de aritmética que transparecem nos escritos de Dewey, especificamente aquelas que dizem respeito à sua concepção de conceito de número, com base nos escritos do historiador Roger Chartier (CHARTIER, 1990, 2009). Também evidenciarei as tensões que os discursos revelam acerca das disputas entre campos com base no lugar social/ institucional a partir do qual os 
autores dos textos analisados "falam". Nesse sentido, articularei o conceito de campo, a partir do sociólogo Pierre Bourdieu (BORDIEU, 1983a, 1983b), com o conceito de lugar social de produção, com base no historiador Michel de Certeau (CERTEAU, 2012).

\section{O manual The Psychology of Number}

O manual The psychology of number (TPN) foi publicado em 1895, nos Estados Unidos, pela editora D. Appleton and Company. Como primeiro autor, consta o canadense James Alexander McLellan, que, segundo a folha de rosto, ocupava o cargo de diretor da Escola de Pedagogia de Ontário, Toronto, e como segundo autor, John Dewey, que era professor de Filosofia na Universidade de Chicago na época da publicação.

Dividido em 16 capítulos, os primeiros tratam da relevância da abordagem psicológica, a natureza do número e sua origem e diversos aspectos que se relacionam à ideia numérica e seu desenvolvimento. Os últimos capítulos têm como foco a discussão de conteúdos específicos (quatro operações, frações, decimais, etc.) e trazem exemplos de exercícios. Portanto, a primeira parte tem um teor mais teórico enquanto que a segunda parte se caracteriza por seu aspecto mais prático. Não pretendo me deter em uma análise mais detalhada do conteúdo do manual no presente trabalho, que será realizada em outro momento, mas cabe destacar algumas concepções que são veiculadas ao longo dos capítulos.

No referido livro (MCLELLAN; DEWEY, 1895), os autores defendem o que eles chamam de "método psicológico", o que seria um contraponto a outros métodos criticados pelos autores, como o método Grube. Além disso, ainda apontam para a potencialidade social da aritmética - assim como de outras disciplinas - ao inserir os estudantes nas realidades do ambiente social. Alguns elementos são retomados de forma recorrente ao longo dos capítulos, como ética, valor e experiência. Vale ressaltar que são temas muito presentes na obra de Dewey, em livros como Democracy and education (1916) e Experience and education (1938). O conceito de experiência, em especial, é bastante enfatizado no TPN, mas não qualquer experiência. Os autores se referem às experiências baseadas em práticas decorrentes de princípios racionais. Nesse sentido, a psicologia desempenha o papel de tornar a experiência racional.

Quanto à origem do número, afirmam que é de natureza psíquica, portanto, ele é um processo racional e não se resume apenas à pura percepção, ao sentido. É possível reduzir as discussões do livro a duas afirmações principais: contar é medir; número é razão. O livro recebeu duras críticas, principalmente de matemáticos, devido às problematizações desenvolvidas pelos autores do TPN em relação a essas afirmações. (MCLELLAN; DEWEY, 1895).

Algumas questões envolvem a escrita do TPN. Afinal, o que explicaria o envolvimento de Dewey na escrita de um manual sobre o ensino de aritmética? De que forma foi dividida a escrita dos capítulos? O que pode ser atribuído a Dewey? Apesar de não ser conclusiva, a análise da correspondência de Dewey, disponível em Hickman (1992), parece indicar que os primeiros capítulos, ou seja, aqueles de cunho mais teórico e que buscam articular a psicologia com a noção de número, foram escritos por Dewey, enquanto que os últimos capítulos, de cunho mais prático, por McLellan ${ }^{5}$. No entanto, não há consenso sobre a divisão exata dos capítulos,

\footnotetext{
${ }^{5}$ Sobre as referências ao TPN na correspondência de Dewey, conferir Rabelo (2016).
} 
John Dewey e os embates sobre a psicologia do número ...

como é possível verificar em Martin (2002), Dalton (2002) e Fallace (2011), ou clareza sobre os critérios que esses estudiosos usaram para concluir qual foi a divisão na escrita do TPN.

\section{A resenha de Dewey sobre o livro The number concept, de Conant}

Levi Leonard Conant (1857-1916) foi um matemático que atuou a maior parte de sua carreira no Worcester Polytechnic Institute (WPI). Ele foi coordenador do departamento de matemática de 1908 até a sua morte e presidente interino do WPI entre 1911 e 1913 (AMERICAN MATHEMATICAL SOCIETY, 2015; WORCESTER POLYTECHNIC INSTITUTE, 2014).

O livro de Conant, sobre o qual Dewey escreveu uma resenha, tem como título The number concept: its origin and development, publicado pela editora Macmillan and Company em 1896. Segundo a folha de rosto, Conant era professor de matemática no Worcester Polytechnic Institute na época em que o livro foi publicado. Iniciado por um prefácio escrito pelo autor, seguido do sumário, o texto é organizado em sete capítulos, encerrando-se com um índice, ao longo de 215 páginas. Os capítulos são: Counting; Number system limits; Origin of number words; Origin of number words (continued); Miscellaneous number bases; The quinary system; The vigesimal system. (CONANT, 1896).

Em linhas gerais, o livro trata de uma abordagem histórico-antropológica sobre os sistemas de numeração em diferentes países/grupos étnicos, informando palavras e símbolos para designar números e quantidade, e formas de contar em diferentes culturas. É possível perceber que a ênfase maior recai no aspecto antropológico, apesar do autor não explicitar isso como seu objetivo principal. (CONANT, 1896).

A resenha de Dewey acerca do livro de Conant foi publicada na revista Psychological Review em maio de 1896. Em circulação ainda hoje, a Psychological Review foi criada em 1894. É uma publicação da American Psychological Association, fundada em 1892, cujo primeiro presidente foi G. Stanley Hall. Dewey foi presidente da Associação em $1899^{6}$. Também ocuparam a presidência William James, em 1894, e James McKeen Cattell, em 1895.

Por que a resenha foi publicada em uma revista de psicologia? Uma resposta implicaria em saber se a resenha foi encomendada pela revista ou se Dewey enviou a resenha por iniciativa própria. Apesar de não terem sido localizados documentos que apontem para uma resposta, a segunda possibilidade parece ser mais plausível. Como o livro não possui discussões de cunho psicológico, parece pouco provável que o editor da revista encomendasse uma resenha a esse respeito. O fato de Dewey ter publicado o TPN no ano anterior pode tê-lo levado a se interessar pelo livro devido ao título, esperando, talvez, encontrar uma discussão de base psicológica acerca da origem do número, interesse que foi visivelmente frustrado. A forma como Dewey iniciou a resenha reforça essa hipótese:

Apenas uma exceção pode ser feita sobre esse livro - assim como a seu título. O livro não é sobre a origem do conceito de número e nem sobre

\footnotetext{
${ }^{6}$ Informações sobre a American Psychological Association (APA) estão disponíveis em: < http://www.apa.org/ about/apa/index.aspx>. Acesso em: 30 jan. 2018.
} 
o seu desenvolvimento. O livro trata de métodos primitivos de contagem e de modos de expressar ou registrar os resultados de tais contagens. $\mathrm{O}$ título verdadeiro seria: "Sistemas de numeração (ou nomes dos números), suas origens e várias formas” (DEWEY, 1896b, p. 326, tradução nossa) 7 .

A principal crítica de Dewey diz respeito ao título do livro de Conant, apontando para a falta de relação com o conteúdo, principalmente se o leitor estiver esperando por esclarecimentos sobre a psicologia da ideia numérica que o título sugere. Dewey enfatizou esse aspecto, inclusive reproduzindo um trecho do qual discorda:

Vale insistir sobre esta discrepância porque é possível que haja uma pesquisa psicológica com bases antropológicas que combinaria com o título. O autor insiste (na pp. 2-4) que a questão da origem do número está fora dos limites de investigação, com o título do livro ainda o encarando! "Filósofos têm se esforçado em estabelecer certas proposições acerca deste tema, mas, como era esperado, falharam em chegar a uma conclusão." O contexto mostra que o Dr. Conant compreende, por esse tema, a velha controvérsia quanto a se os julgamentos numéricos são a priori ou o resultado da experiência (DEWEY, 1896b, p. 327, tradução nossa).

A forma como Dewey aborda o assunto é a partir do ponto de vista psicológico. Isso é reforçado ao longo da resenha e dá pistas sobre sua concepção de número. A preocupação de Dewey não foi com o viés antropológico, apesar de não negar sua relevância, mas com bases psicológicas, foi essa a lente que ele usou para discutir o conceito numérico. Em outro trecho, ele trouxe mais vestígios de suas representações, ao defender que a noção de número é "um desenvolvimento histórico e evolucionário. Ele surge na raça e no indivíduo. O problema psicológico (e pedagógico) é: sob que circunstâncias, em resposta a que estímulos ou necessidades, em que contexto psíquico, esta noção surge?" (DEWEY, 1896b, p. 327, tradução nossa).

Para Dewey (1986b), a abordagem de Conant (1896) é predominantemente antropológica e as informações sobre a composição dos nomes dos números são úteis ao filólogo, mas não contemplam o psicólogo, apesar do potencial que o livro apresenta para tanto. Dewey apontou aspectos do livro que poderiam ter sido desdobrados de forma a contemplar o psicólogo. Em um dos trechos, Dewey explicou:

É incontestavelmente verdade, como observa o Dr. Conant (p. 72), que o selvagem não diferencia a ideia numérica da imagem concreta de dedos ou qualquer que seja o objeto com o qual relaciona, ou seja, ele não abstrai conscientemente. Mas é igualmente verdade que este pensamento contínuo de referência adiante ou para trás em relação a números maiores é consi-

${ }^{7}$ Todas as traduções no presente artigo são de responsabilidade da autora. 
derado psicologicamente um movimento de abstração (DEWEY, 1896b, p. 328, tradução nossa).

No fragmento anterior, Dewey chamou a atenção para o processo de abstração, da passagem do concreto para o abstrato. Vale ressaltar que o conceito de abstração é longamente explorado no TPN. Outro aspecto abordado no TPN e que Dewey retomou na resenha foi a relação entre número e razão, como é possível verificar no seguinte trecho: "Enquanto que um estudo cuidadoso das circunstâncias reais sob as quais os selvagens usam números seria necessário para justificar a afirmação de que no número o elemento razão vem cedo à consciência, o material filológico coletado pelo Dr. Conant aponta nessa direção.” (DEWEY, 1896b, p. 328, tradução nossa).

Algo evidente na resenha de Dewey é que ele fala a partir da psicologia. É esse o lugar que ele assume em seu discurso e com o qual ele se identifica. As críticas que são feitas são principalmente em relação à psicologia, apesar de Dewey também destacar questões pertinentes à filologia e à antropologia. Por outro lado, Conant era um matemático e o seu trabalho, apesar do título, como o próprio Dewey observou, dialoga muito mais com a antropologia e, de certa forma, com a história da matemática.

Em suma, a apreciação de Dewey é feita observando a relevância do livro para o psicólogo e a discussão dos conceitos tem a psicologia como referência. O seu lugar institucional lhe confere autoridade (CERTEAU, 2012) para escrever a resenha sobre o livro de Conant, tanto devido à sua vinculação à psicologia quanto por ter escrito um livro que discute, a partir da psicologia, o conceito de número.

\section{A resposta de Dewey à resenha de Fine}

Henry Buchard Fine (Chambersburg, Pensilvânia, EUA, 1858-Princeton, Nova Jérsei, EUA, 1928) foi um matemático que trabalhou a maior parte de sua vida na Universidade de Princeton, onde atuou por mais de cinquenta anos, como aluno e como professor. Fine se graduou no College of New Jersey em 1880. Em 1884 foi para Leipzig, na Alemanha, onde obteve o Ph. D. em matemática em 1885, sob orientação de Felix Klein. Ao retornar aos EUA, ocupou o cargo de professor assistente em Princeton até 1889. Em 1889 assumiu como professor titular. Foi um dos fundadores da American Mathematical Society, da qual foi presidente em 1911 e 1912. Também foi membro da American Philosophical Society. (HENRY..., 1929; VEBLEN, 1929).

Fine (1896) escreveu a resenha sobre o TPN em 31 de dezembro de 1895, sendo publicada na edição de janeiro pela revista Science. Fine iniciou a apreciação sobre o TPN afirmando que o livro "faz uma análise equivocada do conceito de número, mas defende métodos de ensino de aritmética que são na maior parte bons" (FINE, 1896, p. 134, tradução nossa). Dentre as críticas, as principais foram sobre o tratamento do número como de natureza e de origem essencialmente métricas. Apesar de reconhecer que em partes é verdade, considera que a abordagem foi levada aos extremos, como nas afirmações de que "número é razão" e "contar é medir", argumentando que:

A objeção imediata a tudo isso é que é muito artificial para ser razoável. $\mathrm{E}$ de fato requer apenas um pouco de reflexão para se convencer que o 
número em si não é métrico e que contar não é medir, mas algo muito mais simples que os homens devem ter contado muito antes que eles soubessem como medir [...] (FINE, 1896, p. 134, tradução nossa).

A argumentação de Fine (1896) se fundamenta na abordagem puramente matemática. Ele evocou figuras como Gauss, Newton e Kronecker para reforçar seus argumentos. Com relação às críticas ao tratamento teórico dado pelos autores do TPN, ele é taxativo: "Contar, portanto, não é medir e número não é razão. O número em si não pertence aos conceitos métricos, mas aos conceitos matemáticos não-métricos" (FINE, 1896, p. 135, tradução nossa).

Ele não remeteu a outras áreas do conhecimento, como a psicologia. O lugar do qual ele fala, e com base no qual ele quer dar legitimidade à sua argumentação e deslegitimar o TPN, é a matemática. Na conclusão de sua apreciação do TPN, ele afirmou:

É uma pena que um livro na maior parte tão acertado em relação à prática esteja tão errado em pontos fundamentais da teoria. O que resta é lamentar que os seus autores não se preocuparam, antes de escrever, em ler o que os matemáticos do século atual tinham a dizer sobre as questões com as quais eles pretendiam lidar. (FINE, 1896, p. 136, tradução nossa).

Portanto, a crítica, como é possível perceber no fragmento anterior, diz respeito ao fato de Dewey e McLellan não terem dialogado com os matemáticos, ou seja, não utilizaram do recurso ao discurso autorizado para atribuir legitimidade e autoridade ao manual. Nesse caso, ao contrário da resenha sobre o livro de Conant, a instituição não conferiu autoridade a Dewey, pois esta era a psicologia, e apenas uma autoridade vinculada à matemática conferiria legitimidade às representações contidas no TPN. No fragmento também ficou explícita a crítica à parte teórica. Isso levanta questões quanto à natureza dos ataques de Fine, se teriam sido uma crítica direta a Dewey já que, como estudiosos têm afirmado, McLellan ficou responsável pela segunda parte do livro, de cunho mais prático. McLellan já havia publicado livros de matemática no Canadá, o que poderia indicar que Fine mirava as críticas no psicólogo e poupava o matemático.

$\mathrm{Na}$ carta-resposta à resenha de Fine, Dewey iniciou apontando que Fine levantou questões de "importância considerável para educadores e psicólogos” (DEWEY, 1896a, p. 286, tradução nossa). Nesse fragmento, são dois grupos que ele destaca e aos quais a discussão do livro seria de interesse: os educadores e os psicólogos. O lugar do qual Dewey fala é o da psicologia. E os educadores, quem estaria incluído nesse grupo? Os professores da escola elementar? E os professores das universidades? Ele não citou os matemáticos. Estaria incluindo-os entre os educadores? Ou simplesmente estaria excluindo-os?

Ao rebater as críticas de Fine, que são sempre feitas com base no rigor teórico matemático, Dewey delimita o lugar a partir do qual fala, e explicita o lugar a partir do qual não fala, ou seja, a instituição (CERTEAU, 2012). Nesse sentido, ao defender a assertiva de que contar é medir, ele esclarece que:

[...] mensuração é uma palavra tanto de sentido mais geral quanto de sentido mais técnico. Assim, no sentido matemático mais técnico, de que contar não é medir, é visivelmente aceito no referido livro. No entanto, como é 
defendido no sentido mais amplo do termo que é um processo de medir, e que o modo técnico de medir é uma consequência, psicologicamente, do sentido mais amplo e livre, essa desaprovação importa, talvez, muito pouco (DEWEY, 1896a, p. 286, tradução nossa).

É justamente ao rebater as críticas de Fine (1896) e defender a proposta do TPN que Dewey traz elementos que apontam para suas concepções acerca do conceito de número. Ele argumentou que o número "tem sua gênese psicológica na necessidade de valoração", e que qualquer processo de definição de valor é "uma forma de mensuração no sentido mais amplo daquele termo" (DEWEY, 1896a, p. 286, tradução nossa). A argumentação principal para rebater as críticas em relação aos equívocos teóricos feitos por Fine é a de que os conceitos são usados em um sentido mais amplo, que não correspondem ao rigor matemático.

Em outras palavras, alguém que não tenha atingido o interesse abstrato do matemático (e certamente uma criança que será educada não atingiu) conta apenas quando há algum valor a ser averiguado [...] Portanto, considerando o conteúdo em seu desenvolvimento e não no estágio do matemático quando abstrações já se tornaram concretas, enumeração é sempre para definir valor, isto é, para medir (DEWEY, 1896a, p. 287, tradução nossa).

Dewey fez críticas ao rigor defendido pelos matemáticos em termos conceituais e teóricos. Na sua percepção, os "livros de álgebra, geometria e análise avançada são quase totalmente escritos do ponto de vista de uma exposição elegante e lógica do conteúdo na visão do matemático instruído. Esses livros são muito bons para alguém que não precisa mais deles" (DEWEY, 1896a, p. 288, tradução nossa).

Apesar de Dewey falar a partir da psicologia, ele reconhece o diálogo necessário entre a psicologia e a matemática, encerrando sua resposta com os seguintes dizeres:

Se os psicólogos se arriscarem a alguns descuidos em torno de conceitos matemáticos, e os matemáticos reconhecerem a relevância da demanda psicológica e se aventurarem a alguns descuidos daquele lado, ambos os grupos não apenas podem chegar a um entendimento como o ensino de matemática pode conseguir o que tanto lhe falta atualmente, alguma conexão com as necessidades psíquicas e atitudes daqueles sob instrução. (DEWEY, 1896a, p. 288-299, tradução e grifos nossos).

Todavia, o que o fragmento anterior deixa transparecer de forma sutil é que o ponto principal é a psicologia.

\section{A resposta de Dewey ao artigo de Phillips}

Poucas informações foram encontradas sobre Daniel Edward Phillips (1865- ?), apenas que publicou livros e artigos sobre psicologia e que foi professor na Clark University e, posteriormente, na University of Denver. 
$\mathrm{O}$ artigo de Phillips, intitulado Number and its application psychologically considered, foi publicado em outubro de 1897 na revista Pedagogical Seminary, contendo 61 páginas. É interessante destacar que a referida revista foi fundada por G. Stanley Hall, o qual era o editor responsável quando Phillips publicou o artigo.

O artigo de Phillips (1897) não é sobre o TPN, no entanto, remete a ele em vários momentos, tecendo críticas. A partir do artigo de Phillips (1897), seguiu-se uma réplica de Dewey (1898) que, por sua vez, contou com uma tréplica de Phillips (1898), aparentemente encerrando a discussão veiculada na revista. Como o objetivo é analisar as representações de Dewey, não abordarei a resposta dada por Phillips.

Um dos pontos centrais de Phillips (1897) foi defender a natureza do número baseada na ideia de série. Ele iniciou o artigo fazendo menção a experimentos realizados no laboratório de Wundt ${ }^{8}$. Ainda remeteu a autores como G. Stanley Hall, William James e James Cattel para reforçar suas análises.

A primeira referência ao TPN aparece quando Phillips afirmou que apresentaria as abordagens mais apropriadas para falar de número, a partir de uma perspectiva psicológica e pedagógica, assim como trataria das abordagens inadequadas. Nos dizeres de Phillips:

\begin{abstract}
Na maioria das abordagens sobre esse assunto, um erro é cometido ao tratá -lo ou do ponto de vista da psicologia do adulto, às vezes da filosofia, ou ao considerar um conceito como tendo um surgimento repentino ao invés de ter estágios de desenvolvimento. Que o conceito primeiro se manifesta na consciência com a palavra ou com o símbolo linguístico que o representa é uma concepção pedagógica equivocada ainda muito presente, e que já foi incorporada por muitos que escreveram sobre número e matemática. $\mathrm{Na}$ parte prática do livro The Psychology of Number, de Dewey e McLellan, pode-se inferir que eles acreditam que a criança entra na escola com pouco, se algum, conceito de número (PHILLIPS, 1897, p. 226, tradução nossa).
\end{abstract}

Ele destacou que, na concepção de Dewey e McLellan, o desenvolvimento do conceito de número se dá a partir da necessidade de medir coisas, mas que é "um absurdo imaginar um selvagem tentando medir uma dada quantidade sem qualquer conceito de número" (PHILLIPS, 1897, p. 227, tradução nossa). Phillips evoca o TPN principalmente quando defende a ideia de número baseada em série e, para tanto, tenta invalidar a ideia baseada em razão. Segundo Phillips, a ideia de razão para tratar do conceito de número seria incompleta, consistindo em apenas uma parte da ideia de série.

Em síntese, as críticas de Phillips (1897) ao TPN dizem respeito à relação entre número, mensuração e razão, sendo que ele considera que a ideia de número baseada nos conceitos de razão e de mensuração são apenas aspectos complementares da ideia de número enquanto série. Ao considerar que o artigo de Phillips foi publicado em 1897, é possível que tenha lido

\footnotetext{
${ }^{8}$ O laboratório de Wilhelm Wundt, em Leipzig, foi uma importante referência nas pesquisas educacionais com bases psicológicas e recebeu diversos pesquisadores dos EUA no final do século XIX e início do XX. (LAWN, 2014).
} 
as resenhas escritas sobre o TPN entre 1895 e 1896, tendo familiaridade com as críticas tecidas por psicólogos e matemáticos, incluindo aquelas que diziam respeito à relação entre número, razão e mensuração. Portanto, não é de se descartar que Phillips tenha mirado nestes aspectos como uma estratégia para legitimar suas análises e se respaldar de possíveis críticas vinda dos mesmos grupos.

Apesar do estudo de Phillips partir da psicologia, os ataques ao TPN revelam as disputas dentro do próprio campo. Ao longo de todo o artigo, há o recurso ao discurso autorizado (CERTEAU, 2012), legitimado por um saber instituído, vinculado à psicologia experimental, ao citar psicólogos como James, Hall e Cattell e ao mencionar os experimentos no laboratório de Wundt, Phillips argumenta a partir da psicologia de bases experimentais, que começou a se estruturar no final do século XIX e conquistou espaço nos EUA.

Outro aspecto que chamou a atenção no artigo de Phillips (1897) foi que o nome de Dewey aparece sempre em primeiro lugar, mesmo que o primeiro autor do TPN tenha sido McLellan. Mesmo que não tenha sido intencional, deixa transparecer o sujeito que estava sendo questionado, a figura de autoridade em questão, ou seja, Dewey.

Dentre os três textos de Dewey analisados no presente artigo, a resposta ao artigo de Phillips é o mais revelador acerca da sua voz devido à sua extensão e ao nível de detalhamento ao explicar alguns conceitos contidos no TPN. Dewey iniciou a resposta comentando sua compreensão da teoria apresentada por Phillips, ou seja, sobre a origem do número baseada na ideia de série.

Esta teoria, como a entendo, separa o processo de contagem, no qual o número inquestionavelmente tem sua origem e desenvolvimento, da percepção de quantidade, defendendo que a ideia de número na forma de série é um processo psicologicamente e pedagogicamente distinto da ideia de razão; ou, como é afirmado na síntese da página 277: Número enquanto mensuração não é o todo do desenvolvimento do número, mas apenas o lado complementar da ideia de série; número enquanto mensuração não é capaz de explicar todos os fenômenos mentais dos números. (DEWEY, 1898, p. 426, tradução nossa).

Segundo Dewey (1898, p. 426, tradução nossa), é difícil se convencer que “o Sr. Phillips não distinguiu duas questões totalmente diferentes como nomear uma série de números e repetir uma série de nomes de números". Em alguns momentos Dewey admite uma possível falta de clareza em trechos do TPN. Para ele, a moral do TPN, do ponto de vista pedagógico, pode ser resumida da seguinte forma:

Não ensine número de forma meramente mecânica ou meramente racional. Dê à criança algo para fazer que envolva o uso de considerações numéricas de forma relacionada que seja razoável. Assim, ela ganhará familiaridade prática com os números por meio do uso visando algum propósito e finalidade, ao invés de algo sem sentido e casual. Ela estará formando hábitos práticos e ordenados de relacionar, o que posteriormente se tornará consciente na generalização real. (DEWEY, 1898, p. 429, tradução nossa). 
Do artigo-resposta de Dewey é possível resumir as seguintes concepções: a ideia de série não antecede o processo de contagem na origem do conceito de número, na verdade, a origem do número se dá no processo de contagem. Ainda em relação à ideia de série, a repetição dos números não é o mesmo que contar. Entre suas concepções, ele explicita que a atividade prática precede a racional na origem e no desenvolvimento do conceito de número. Ainda que contar, formação das séries e mensuração se dão em conjunto, e que "número enquanto número é enumeração” (DEWEY, 1898, p. 430, tradução nossa, grifos do autor).

\section{Algumas considerações sobre disputas entre campos e o conceito de número}

Os escritos de Dewey analisados no presente artigo evidenciam as disputas entre campos e a busca de legitimação com base em um discurso autorizado por um lugar/instituição (CERTEAU, 2012). Há uma polarização da discussão entre a matemática e a psicologia. O que está em disputa é a determinação da instituição que detém autoridade para arbitrar sobre o ensino de aritmética, ou seja, a luta pelo monopólio dessa autoridade (BOURDIEU, 1983a). Também se verificam disputas dentro do mesmo campo, como o caso da psicologia, nos textos de Phillips (1897) e Dewey (1897), lutas entre o novo e o dominante (BOURDIEU, 1983b), uma psicologia de bases experimentais que cada vez mais conquista espaço na virada do século XIX para o XX.

A análise realizada por Rabelo (2016) de algumas resenhas sobre o TPN, que foram escritas na mesma época de sua publicação, revela que as críticas ao manual são feitas tanto em relação à abordagem matemática quanto à abordagem psicológica. Os psicólogos questionam a legitimidade da teoria psicológica empregada enquanto os matemáticos questionam o rigor e a validade dos conceitos matemáticos. Ou seja, cada sujeito busca delimitar e proteger seu campo de atuação ao questionar a legitimidade do TPN em um campo ou outro.

Nas respostas escritas por Dewey à resenha de Fine (1896), ao artigo de Phillips (1897) e na resenha sobre o livro de Conant (1896), ele assume o lugar institucional da psicologia. A sua justificativa para a falta de rigor matemático no tratamento de diversos conceitos é o de que não está escrevendo para matemáticos, portanto, o nível de rigor é diferente.

Certamente, Dewey se mostrou uma ameaça à autoridade dos matemáticos, posto que ele, uma figura conhecida no cenário educacional nos EUA, principalmente pelas discussões sobre psicologia/filosofia, resolveu publicar um livro sobre o ensino de aritmética. No caso da psicologia, a disputa tem uma natureza um pouco diferente, tratando-se de disputas entre vertentes teóricas dentro do mesmo campo e da delimitação de quem são as autoridades.

Os embates entre campos também incidem nas diferentes representações acerca da natureza do conceito de número. Basta lembrar que foi esse o ponto de crítica de Dewey sobre o livro de Conant, em que Conant (1896) tratou o conceito de número a partir do viés antropológico, mesmo que de forma intuitiva e que não tenha sido essa a sua intenção inicial. Fine (1896), por sua vez, sempre evocou o rigor matemático. Phillips (1897) desenvolveu sua argumentação com base na psicologia experimental. Já Dewey tratou o conceito de número a partir do viés psicológico com bases filosóficas. É difícil apontar vencedores, visto que eles falam a partir de lugares diferentes e, portanto, apresentam representações diversas (CHARTIER, 2009) do conceito de número, de sua origem e de seu desenvolvimento. 
Seria interessante verificar a recepção dos textos de Conant (1896) e de Phillips (1897) e compará-la às apreciações feitas por Dewey, o que certamente revelaria até que ponto as representações de Dewey tinham eco entre educadores, psicólogos e matemáticos. Por exemplo, o que outros matemáticos e/ou psicólogos escreveram sobre o livro de Conant ou sobre o artigo de Phillips? Há proximidades com as críticas feitas por Dewey? Esta seria uma análise relevante e provavelmente apontaria para mais disputas entre campos, e mesmo dentro dos próprios campos, com representações divergentes.

Dentre as concepções de Dewey (1896a, 1896b, 1898) que são apreendidas por meio dos textos analisados, é possível concluir que ele manteve as assertivas de que "número é razão" e de que "contar é medir", mas esclarece que não o fez com o rigor do matemático, ele o fez de outro lugar, que permite uma abordagem mais ampla. Ele reitera que a origem do número se dá no processo de contagem, apesar de reconhecer que contagem, formação de séries e mensuração ocorrem em conjunto.

Tais elementos são passíveis de confronto com o TPN para identificar o que pode ser atribuído a Dewey no referido manual ou, ao menos, o que pode ser dito como ideias das quais Dewey compartilhava naquele momento. Ainda considerando o período em que o TPN e os textos analisados no presente artigo foram publicados, década de 1890, período esse que é considerado pelos estudiosos de Dewey como uma fase de transição em seu pensamento, de uma abordagem hegeliana para uma pragmática, cabe questionar se as concepções acerca do conceito de número presentes nos referidos escritos se repetiram em suas produções posteriores ou em que medida tais concepções se alteraram. Estas são apenas algumas questões, entre várias, sobre as publicações de Dewey que remetem à educação matemática, que permanecem em aberto.

\section{Agradecimentos}

A autora agradece o apoio da Fundação de Amparo à Pesquisa do Estado de São Paulo (FAPESP), Processos 2012/11361-1 e 2013/03523-4.

\section{Referências}

AMERICAN MATHEMATICAL SOCIETY. Levi L. Conant prize. 2015. Disponível em: <http:/ /www.ams.org/profession/prizes-awards/ams-prizes/conant-prize>. Acesso em: 29 out. 2015.

BOURDIEU, P. O campo científico. In: ORTIZ, R. (Org.). Pierre Bourdieu: sociologia. São Paulo: Ática, 1983a.

Questões de sociologia. Rio de Janeiro: Marco Zero, 1983b.

CERTEAU, M. História e psicanálise: entre ciência e ficção. 2. ed. Belo Horizonte: Autêntica, 2012.

CHARTIER, R. A história cultural: entre práticas e representações. Rio de Janeiro: Bertrand Brasil, 1990. 
CHARTIER, R. A história ou a leitura do tempo. Belo Horizonte: Autêntica, 2009.

CONANT, L. L. The number concept: its origin and development. New York: Macmillan, 1896. Disponível em: <https://archive.org/details/numberconceptit00conagoog>. Acesso em: 30 jan. 2018.

DALTON, T. C. Becoming John Dewey: dilemmas of a philosopher and naturalist. Bloomington: Indiana University Press, 2002.

DEWEY, J. Democracy and education: an introduction to the philosophy of education. New York: Macmillan, 1916.

. Experience and education. New York: Macmillan, 1938.

Psychology. New York: Harper, 1887.

. Psychology of number. Science, Washington, v. 3, n. 60, p. 286-289, Feb. 21, 1896 a.

Disponível em: <http://www.jstor.org/stable/1623160>. Acesso em: 30 jan. 2018.

Review of the number concept: its origin and development. Psychological

Review, Washington, v. 3, n. 3, p. 326-329, 1896b. Disponível em: <http://dx.doi. org/10.1037/h0065886>. Acesso em: 30 jan. 2018.

Some remarks on the psychology of number. Pedagogical Seminary, Philadelphia, v. 5, p. 426-434, Jan. 1898. Disponível em: <https://brocku.ca/MeadProject/Dewey/ Dewey_1898e.html>. Acesso em: 30 jan. 2018.

ESPACIO, TIEMPO Y EDUCACIÓN. Salamanca: FahrenHouse, v. 3, n. 2, 2016. Disponível em: <http://www.espaciotiempoyeducacion.com/ojs/index.php/ete/issue/ view/6>. Acesso em: 30 jan. 2018.

FALLACE, T. D. Dewey and the dilemma of race: an intellectual history, 1895-1922. New York: Teachers College Press, 2011.

FINE, H. B. The psychology of number and its applications to methods of teaching arithmetic: by James A. McLellan, A. M., L1.D., and John Dewey, Ph. D. Science, Washington, v. 3, n. 56, p. 134-136, 24 Jan. 1896. Disponível em: < http://doi.org/10.1126/ science.3.56.134-a>. Acesso em: 30 jan. 2018.

HENRY Burchard Fine. Science, Washington, v. 69, n. 1780, p. 150-151, 1929. Disponível em: <https://doi.org/10.1126/science.69.1780.150>. Acesso em: 29 jan. 2018.

HICKMAN, L. (Ed.). The correspondence of John Dewey, 1871-1952 (I-IV): electronic edition. Charlottesville: InteLex, 1992.

LAWN, M. Um conhecimento complexo: o historiador da educação e as circulações transfronteiriças. Revista Brasileira de História da Educação, Maringá, v. 14, n. 1, p. 127-144, 2014. Disponível em: <http://rbhe.sbhe.org.br/index.php/rbhe/article/ view/615/pdf_2>. Acesso em: 30 jan. 2018.

MARTIN, J. The education of John Dewey: a biography. New York: Columbia University Press, 2002. 
John Dewey e os embates sobre a psicologia do número ...

MCLELLAN, J. A. Applied psychology: an introduction to the principles and practice of education. Toronto: The Copp, Clark Company, 1889.

MCLELLAN, J. A.; DEWEY, J. The psychology of number and its applications to methods of teaching arithmetic. New York: D. Appleton, 1895.

PHILLIPS, D. E. Number and its application psychologically considered. Pedagogical Seminary, Worcester, v. 5, n. 2, p. 221-281, 1897. Disponível em: <htps://doi.org/10.1080/ 08919402.1897.10534358>. Acesso em: 30 jan. 2018.

Some remarks on number and its application. Pedagogical Seminary, Worcester, v. 5, n. 4, p. 590-598, 1898. Disponível em: <https://doi.org/10.1080/08919402.1898.10534 036>. Acesso em: 30 jan. 2018.

POPKEWITZ, T. S. (Ed.). Inventing the modern self and John Dewey. New York: Macmillan, 2008.

RABELO, R. S. Destinos e trajetos: Edward Lee Thorndike e John Dewey na formação matemática do professor primário no Brasil (1920-1960). 2016. 286f. Tese (Doutorado em Educação) - Universidade de São Paulo, São Paulo, 2016.

. O livro "The psychology of number" de McLellan e Dewey. In: CONGRESO

IBEROAMERICANO DE HISTORIA DE LA EDUCACIÓN LATINOAMERICANA, 11., 2014, Toluca, México. Anais... Toluca: El Colegio Mexiquense, 2014.

SCHIRIEWER, J.; BRUNO-JOFRÉ, R. C. (Ed.). The global reception of John Dewey's thought: multiple refractions through time and space. New York: Roudledge, 2012.

STEMHAGEN, K. Beyond absolutism and constructivism: the case for an evolutionary philosophy of mathematics education. 2004. 216f. Thesis (Ph. D.) - University of Virginia, Charlottesville, 2004.

VEBLEN, O. Henry Burchard Fine: in memoriam. Bulletin of the American

Mathematical Society, Lancaster, v. 35, n. 5, p. 726-730, 1929. Disponível em: <http:// projecteuclid.org/euclid.bams/1183493477>. Acesso em: 29 out. 2015.

WORCESTER POLYTECHNIC INSTITUTE. 2014 Levi L. Conant lecture series. Disponível em: <https://web.wpi.edu/Images/CMS/Mathematics/2014-053_Conant_ POSTER_Huerta.pdf $>$. Acesso em: 19 jul. 2017.

Artigo recebido em 15/08/2016. Aceito em 08/08/2017.

Endereço para contato: Rua Butantan, 235, Caixa Postal 61528, CEP 05424-970, Pinheiros, São Paulo, SP, Brasil. 